Research Article

\title{
Functionalized $\mathrm{Fe}_{3} \mathrm{O}_{4}$ Magnetic Nanoparticle Potentiometric Detection Strategy versus Classical Potentiometric Strategy for Determination of Chlorpheniramine Maleate and Pseudoephedrine $\mathrm{HCl}$
}

\author{
Azza A. Moustafa, ${ }^{1}$ Maha A. Hegazy, ${ }^{1}$ Dalia Mohamed, ${ }^{2,3}$ and Omnia Ali $\mathbb{D}^{2}$ \\ ${ }^{1}$ Analytical Chemistry Department, Faculty of Pharmacy, Cairo University, Kasr-El Aini Street, 11562 Cairo, Egypt \\ ${ }^{2}$ Analytical Chemistry Department, Faculty of Pharmacy, October University for Modern Sciences and Arts (MSA), \\ 11787 6th October City, Egypt \\ ${ }^{3}$ Analytical Chemistry Department, Faculty of Pharmacy, Helwan University, Ein Helwan, 11795 Cairo, Egypt
}

Correspondence should be addressed to Omnia Ali; dr.omniali@gmail.com

Received 26 September 2018; Revised 10 January 2019; Accepted 4 February 2019; Published 25 February 2019

Academic Editor: Antony C. Calokerinos

Copyright (c) 2019 Azza A. Moustafa et al. This is an open access article distributed under the Creative Commons Attribution License, which permits unrestricted use, distribution, and reproduction in any medium, provided the original work is properly cited.

\begin{abstract}
Nanosized adsorbents when used in potentiometric methods of analysis usually show better performance rather than the traditional potentiometric approach; this is attributed to the high specific surface area of the nanomaterial used in addition to the lack of internal diffusion resistance, thus improving their adsorption capacity. In the presented work, a rapid and sensitive potentiometric determination of chlorpheniramine maleate (CPM) and pseudoephedrine hydrochloride (PSE) in pure form, in pharmaceutical preparation, and in biological fluid was developed based on functionalized magnetic nanoparticles $\left(\mathrm{Fe}_{3} \mathrm{O}_{4}\right)$. This strategy was compared with the classical potentiometric strategy. Three types of sensors were constructed using phosphotungstic acid (PTA), $\beta$-cyclodextrin $\left(\beta\right.$-CD), and $\beta$-cyclodextrin-conjugated $\mathrm{Fe}_{3} \mathrm{O}_{4}$ magnetic nanoparticles for the potentiometric determination of each of CPM and PSE. The prepared sensors were characterized in regards to their composition, life duration, working $\mathrm{pH}$ range, and response time. The sensors have demonstrated promising selectivity to CPM and PSE in the presence of pharmaceutical formulation excipients, plasma matrix, and a diversity of both organic and inorganic interfering materials. The developed sensors have displayed good responses. Statistical comparison of the achieved results with a reported method has revealed no significant difference regarding both accuracy and precision.
\end{abstract}

\section{Introduction}

Chlorpheniramine maleate (CPM) is (3-(4-chlorophenyl)$N, N$-dimethyl-3-pyridin-2-yl-propan-1-amine (Figure 1(a)). CPM is considered as a first-generation alkylamine antihistamine which is mainly prescribed to inhibit allergy symptoms as rhinitis and urticaria. CPM can give rise to a moderate degree of sedation [1]. Pseudoephedrine hydrochloride (PSE) is also known as $[(+)$-threo- $\alpha$ - $[1-$ methylamino) ethyl] benzyl alcohol] hydrochloride (Figure 1(b)). PSE is a sympathomimetic amine drug which is administered for its bronchodilator and nasal decongestant effects as it has the ability to contract the swollen mucous membranes, decrease the nasal airway obstruction, and reduce tissue hyperemia [2]. Ibuprofen (IBF) is [(2S)-2-(4isobutylphenyl) propanoic acid] (Figure 1(c)). IBF is a nonsteroidal anti-inflammatory drug (NSAID) which is utilized due to its ability to relief pain, treat fever, and reduce inflammation [3].

CPM, PSE, and IBF are coformulated drugs in a single dosage from which is utilized for treating the symptoms cough and common cold.

A detailed survey for the reported methods that were utilized for the analysis of CPM, PSE, and IBF has revealed 


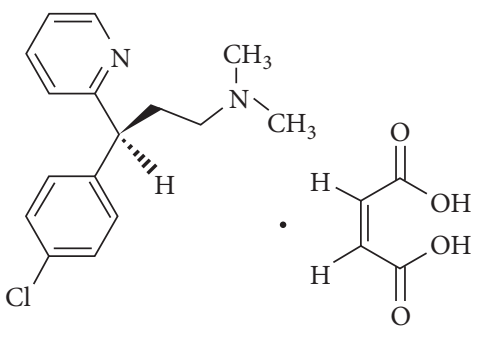

(a)<smiles>CC(C)Cc1ccc(C(C)C(=O)O)cc1</smiles><smiles>CN[C@H](C)[C@H](O)c1ccccc1</smiles>

(b)

Figure 1: Chemical structure of (a) CPM, (b) PSE, and (c) IBF.

that these drugs were determined either singly or in their binary mixtures by spectrophotometry [4, 5], HPTLC [6], HPLC-MS and GC-MS [7-9], HPLC-UV [10], capillary electrophoresis $[11,12]$, and potentiometry [13-22]. However, only one method was found for the simultaneous determination of the three drugs based on liquid chromatography with experimental design [23].

Analytical methods involving molecular host-guest approaches have attracted tremendous concern due to their high selectivity. Cyclodextrins as ionophoric polymers are extensively recognized to compose stable inclusion complexes with a variety of organic, inorganic, and biological guest molecules in their lipophilic cavities while demonstrating high molecular selectivity as well as enantioselectivity $[24,25]$.

Functionalized magnetite nanoparticles have the ability to be widely dispersed in the analyte solution and intensely stimulate the chemical reaction between their functional groups and the target analyte, and this is attributed to their considerably lower diffusion layer thickness in contrast to their bulk counterparts. Magnetic nanoparticles are among the particles that were actively examined, where based on their interesting magnetic properties, they are evolving as possibly useful tools for a wide variety of applications [26] due to, for example, their successful usage as a new approach in potentiometric analysis of drugs in different pharmaceutical preparations [27].

In view of the previously mentioned points of view, we aimed to develop a new potentiometric approach utilizing magnetic nanoparticles for the rapid and sensitive quantification of CPM and PSE in their bulk powder, pharmaceutical dosage form, and plasma samples without interference from IBF. The proposed study has demonstrated certain encouraging improvements to the use of $\beta$-cyclodextrin. The achieved results were compared to the classical potentiometric methods.

\section{Experimental}

2.1. Apparatus. Potential measurements were carried out using a Jenway digital ion analyzer model 3505 (Jenway, UK) with $\mathrm{Ag} / \mathrm{AgCl}$ double junction reference electrode (Aldrich, USA). The $\mathrm{pH}$ adjustment was performed utilizing a Jenway $\mathrm{pH}$ glass electrode (Jenway, UK). Imaging of Iron oxide magnetite nanoparticles was performed with the aid of a JEOL JEM-2100 high-resolution transmission electron microscope where the accelerating voltage was adjusted to $200 \mathrm{kV}$.

\subsection{Chemicals and Reagents}

2.2.1. Pure Samples. Chlorpheniramine maleate (CPM) with a purity of $99.72 \pm 1.065$ and pseudoephedrine $\mathrm{HCl}$ (PSE) with a purity of $99.45 \pm 1.011$ were provided from Egyptian International Pharmaceutical Industries Co. (EIPICO), Cairo, Egypt. Ibuprofen (IBF) with a purity of $100.05 \pm 1.357$ was provided from GlaxoWellcome, Egypt. The purity of the three drugs was checked by a reported method [23].

2.2.2. Market Sample. Sinlerg ${ }^{\circledR}$ coated tablets (Eva Pharma for pharmaceuticals and medical appliance S.A.E, Haram, Giza, Egypt) with batch number: 212314 were obtained from the local market. Each tablet is composed of $2 \mathrm{mg}$ of CPM, $30 \mathrm{mg}$ of PSE, and $200 \mathrm{mg}$ of IBF as labelled.

2.2.3. Chemicals and Reagents. All chemicals and reagents used were of analytical reagent grade. High-molecular weight polyvinyl chloride (PVC), $\beta$-cyclodextrin $(\beta$-CD), dibutyl phthalate (DBP), and phosphotungestic acid $99.97 \%$ (PTA) were purchased from Aldrich (Steinheim, Germany). Tetrahydrofuran (THF) was purchased from Merck (Darmstadt, Germany). Hydrochloric acid, sodium hydroxide, urea, potassium chloride, calcium chloride, and 
potassium dihydrogen phosphate all were purchased from El-Nasr pharmaceutical chemicals (Cairo, Egypt). Plasma was purchased from VACSERA (Egypt). Iron oxide $\left(\mathrm{Fe}_{3} \mathrm{O}_{4}\right)$ magnetite nanoparticles $(5 \mathrm{~nm}$ diameter) were purchased from Nanotech Egypt for photoelectronics Co. (6th of October City, Egypt). According to the manufacturer procedure, $\mathrm{Fe}_{3} \mathrm{O}_{4}$ was synthesized via the coprecipitation method. This method is based on alkaline coprecipitation of ferric and ferrous salts in aqueous solution $[28,29]$. In addition, imaging was performed to confirm the size and shape as demonstrated in Figure 2.

\subsection{Standard Solutions}

2.3.1. Stock Solutions. The stock solutions of both CPM and PSE were prepared separately in the concentration of $\left(10^{-2} \mathrm{M}\right)$ using distilled water as a solvent.

2.3.2. Working Solutions. The working solutions of CPM $\left(10^{-8}-10^{-3} \mathrm{M}\right)$ and PSE $\left(10^{-9}-10^{-3} \mathrm{M}\right)$ were freshly prepared via dilution from the prepared stock solutions using distilled water.

Both the stock and working solutions were stable for at least one month when kept in a refrigerator at $4^{\circ} \mathrm{C}$.

\subsection{Procedures}

2.4.1. Precipitation of the Ion Exchanger. Two aliquots of $10 \mathrm{~mL}$ of $\left(10^{-2} \mathrm{M}\right)$ aqueous standard CPM and PSE solutions were transferred in two different beakers followed by the addition of $10 \mathrm{~mL}$ of aqueous $\left(10^{-2} \mathrm{M}\right)$ of PTA solution on each beaker. The two prepared solutions were mixed well for 5 minutes. The obtained precipitates were filtered through Whatman filter papers and then washed several times using cold distilled water till the precipitate is chloride-free as indicated when tested by $\mathrm{AgNO}_{3}$ solution. The precipitate is then dried at room temperature and ground to be in the form of fine powder. Elemental analysis (carbon, hydrogen, and nitrogen) was performed to check both the formation and purity of the ion-associates as well as the chemical composition of the precipitates as abridged in Table 1.

\subsubsection{Fabrication of PVC-Based Membrane Sensors (Sensors} $1,2,4$, and 5). For the preparation of sensors 1 and 4, $10 \mathrm{mg}$ of the ion exchangers (CPM-PT and PSE-PT) was separately mixed in glass Petri dishes $(5 \mathrm{~cm}$ diameter) with $0.35 \mathrm{ml}$ of DBP and $0.19 \mathrm{~g}$ PVC. While for the preparation of sensors 2 and 5 , the following materials were thoroughly mixed with each other: $0.19 \mathrm{~g}$ PVC with $0.35 \mathrm{ml} \mathrm{DBP}$ and $0.04 \mathrm{~g} \beta$-CD. Subsequently, the obtained mixtures were dissolved in $5 \mathrm{ml}$ THF in Petri dishes $(5 \mathrm{~cm}$ diameter) and homogenized carefully.

The Petri dishes were left overnight at room temperature after being covered with filter papers in order to permit for solvent evaporation. Master membranes were formed with a thickness of about $0.1 \mathrm{~mm}$. Disks of about $\approx 10 \mathrm{~mm}$ diameter were cut from the master membranes, with the aid of a cork

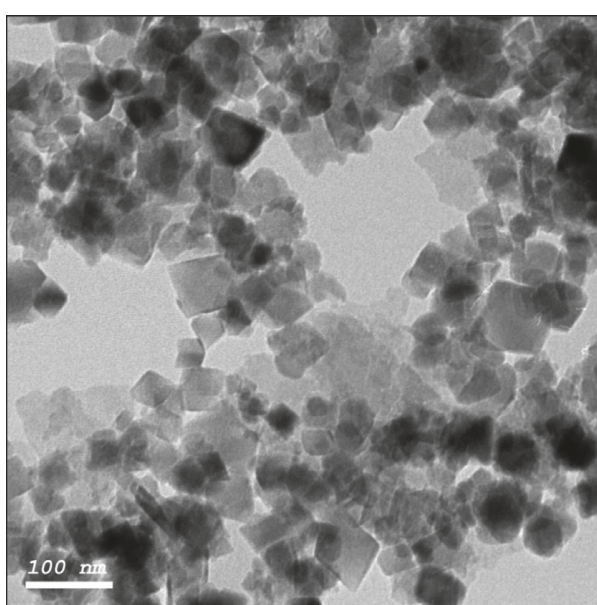

Figure 2: TEM micrograph of $\mathrm{Fe}_{3} \mathrm{O}_{4}$ nanoparticles.

TABLe 1: The elemental analysis of ion associates.

\begin{tabular}{lccccc}
\hline \multirow{2}{*}{ Ion-associates } & $\begin{array}{c}\text { Tentative } \\
\text { formulae }\end{array}$ & Percentage & $\mathrm{C} \%$ & $\mathrm{~N} \%$ & $\mathrm{H} \%$ \\
\hline \multirow{2}{*}{$\mathrm{CPM}-\mathrm{PT}$} & {$\left[\mathrm{C}_{16} \mathrm{H}_{20} \mathrm{ClN}_{2}\right]_{3} \cdot$} & Found & 15.68 & 2.34 & 1.70 \\
& {$\left[\mathrm{PW}_{12} \mathrm{O}_{40}\right]$} & Calculated & 15.55 & 2.27 & 1.62 \\
\hline \multirow{2}{*}{ PSE-PT } & {$\left[\mathrm{C}_{10} \mathrm{H}_{16} \mathrm{NO}_{3} \cdot\right.$} & Found & 10.83 & 1.21 & 1.46 \\
& {$\left[\mathrm{PW}_{12} \mathrm{O}_{40}\right]$} & Calculated & 10.66 & 1.24 & 1.42 \\
\hline
\end{tabular}

borer. The disks were then pasted utilizing THF to interchangeable PVC tips that were clipped into the end of the electrodes glass bodies. Equal separate volumes of $\left(10^{-2} \mathrm{M}\right)$ CPM or PSE and $\left(10^{-2} \mathrm{M}\right) \mathrm{KCl}$ were mixed well where the obtained solution was considered to be the internal reference solution. However, the internal reference electrode was formed through the immersion of an $\mathrm{Ag} / \mathrm{AgCl}$ wire $(1 \mathrm{~mm}$ diameter) in the internal reference solution. Each formed electrode (sensor) was preconditioned by being dipped in $\left(10^{-2} \mathrm{M}\right) \mathrm{CPM}$ and PSE solutions for $24 \mathrm{~h}$.

The electrochemical cell for the potential measurements could be represented as follows: $\mathrm{Ag} / \mathrm{AgCl}$ (internal reference electrode) $/ 1.0 \times 10^{-2} \mathrm{M}$ CPM or PSE solutions, $1.0 \times 10^{-2} \mathrm{M}$ $\mathrm{KCl}$ (internal reference solution)//PVC membrane//test solution ( $\mathrm{pH} 4-8)$ and $(\mathrm{pH} 4-7)$ for CPM and PSE, respectively//Ag/ $\mathrm{AgCl}$ double junction reference electrode. The electrodes were usually kept in deionized water in between the measurements. The fabrications of the four ISE electrodes (sensors 1, 2, 4, and 5) are described in Table 2.

2.4.3. Coating of Nanoparticles with $\beta$-CD and Fabrication of Functionalized $\mathrm{Fe}_{3} \mathrm{O}_{4}$ Nanoparticles Membrane Sensors (Sensors 3 and 6). Coating of nanoparticles with $\beta$-CD, as ionophoric polymer, was achieved through the addition of $0.04 \mathrm{mg} \beta$-CD which is dissolved in $0.35 \mathrm{~mL} \mathrm{DBP}$ as a plasticizer. The components were carefully mixed with $5 \mathrm{~mL}$ THF until the mixture is completely homogenous. Then, $1 \mathrm{~mL}$ of the nanoparticles solution was added, followed by sonication for 15 minutes, and finally, the mixture was left to allow for the evaporation of THF. 
TABLE 2: The composition of the six fabricated sensors.

\begin{tabular}{lrc}
\hline Sensor & Ion-associate & Plasticizer \\
\hline 1 & $\mathrm{CPM}-\mathrm{PT}$ & $\mathrm{DBP}$ \\
2 & $\mathrm{CPM}-\mathrm{CD}$ & $\mathrm{DBP}$ \\
3 & $\mathrm{CPM}-\mathrm{Fe}_{3} \mathrm{O}_{4}$ nanoparticles & DBP \\
4 & $\mathrm{PSE}-\mathrm{PT}$ & $\mathrm{DBP}$ \\
5 & $\mathrm{PSE}-\mathrm{CD}$ & $\mathrm{DBP}$ \\
6 & $\mathrm{PSE}-\mathrm{Fe}_{3} \mathrm{O}_{4}$ nanoparticles & DBP \\
\hline
\end{tabular}

For the fabrication of the functionalized $\mathrm{Fe}_{3} \mathrm{O}_{4}$ nanoparticles membrane sensors, the same procedure for the preparation of sensors ( 2 and 5 ) was repeated as explained in Section 2.4.2.

However, in order to allow for the formation of the inclusion complex between the nanoparticles' functional groups and CPM and PSE, $0.1 \mathrm{~mL}$ of the final magnetic fluid was added to the inner solution (which is composed of equal volumes of $\left(10^{-2} \mathrm{M}\right)$ CPM or PSE and $\left.\left(10^{-2} \mathrm{M}\right) \mathrm{KCl}\right)$ of the membrane electrode of the prepared sensors. The internal reference electrode was formed through the immersion of a $\mathrm{Ag} / \mathrm{AgCl}$ wire ( $1 \mathrm{~mm}$ diameter) in the internal reference solution. The designed sensors (3 and 6) were preconditioned by being dipped in $\left(10^{-2} \mathrm{M}\right) \mathrm{CPM}$ and PSE solutions for 24 hours. The induced membrane potential was measured while applying a magnetic field with the aid of a magnetic stirrer, during the time of sample measurement [26]. The calibration curves were constructed by plotting $E$ $(\mathrm{mV})$ against the corresponding negative concentration logarithm of CPM or PSE.

2.4.4. Sensors Calibration. The conditioned sensors were calibrated through their immersion in about $50 \mathrm{~mL}$ of the working standard solutions equivalent to $1 \times 10^{-8}-1 \times 10^{-3} \mathrm{M}$ and $1 \times 10^{-9}-1 \times 10^{-3} \mathrm{M}$ for $\mathrm{CPM}$ and PSE, respectively. The sensors were in conjunction with the $\mathrm{Ag} / \mathrm{AgCl}$ reference electrode and were permitted to equilibrate with constant stirring utilizing a magnetic stirrer throughout the whole process. The sensors were usually washed with distilled water in between the measurements. The electrode potential of each sensor was recorded after being stabilized to $\pm 2 \mathrm{mV}$ and was plotted against the corresponding negative logarithmic concentration of CPM and PSE. Consequently, the constructed calibration curves were then utilized for the measurement of unknown samples.

2.4.5. Effect of $p H$. As the developed potentials of the six fabricated sensors is influenced by the $\mathrm{pH}$, the effect of $\mathrm{pH}$ was examined within the range of 2-10 utilizing the solutions of CPM and PSE in a concentration equivalent to $10^{-4} \mathrm{M}$ and $10^{-3} \mathrm{M}$, respectively. Both dilute sodium hydroxide and hydrochloric acid solutions were used for $\mathrm{pH}$ adjustment to the required value. The acquired potential for each $\mathrm{pH}$ value was recorded.

2.4.6. Sensors Selectivity. The interference which foreign ions might perform on the response of each fabricated sensor to its primary ion was evaluated using the potentiometric selectivity coefficient- $\log K^{\text {pot. }}$ (primary ion, interferent). The selectivity coefficients were calculated through measurement of the developed potentials from $10^{-3} \mathrm{M}$ aqueous of each of CPM and PSE solution and then for $10^{-3} \mathrm{M}$ aqueous interferent solution. For calculating the potentiometric selectivity, the following equation was used:

$$
\begin{aligned}
\log \left(K^{\text {pot. }} \text { primary ion interferent }\right)= & {\left[\frac{E_{\mathrm{D}}-E_{\mathrm{M}}}{2.303 R T / Z_{\mathrm{D}} F}\right] } \\
& +\left[1-\frac{Z_{\mathrm{D}}}{Z_{\mathrm{M}}}\right] \log [D],
\end{aligned}
$$

where $E_{\mathrm{D}}$ is the potential measured in $10^{-3} \mathrm{M}$ of drug solution for CPM or PSE, $E_{\mathrm{M}}$ is the potential measured in $10^{-3} \mathrm{M}$ interferent solution, $Z_{\mathrm{D}}$ and $Z_{\mathrm{M}}$ are the charges of CPM or PSE and interfering ion, respectively, and $2.303 R T / Z_{\mathrm{D}} F$ represents the slope of the investigated sensor ( $\mathrm{mV} /$ concentration decade).

2.4.7. Application to Pharmaceutical Dosage Forms. Ten Sinlerg ${ }^{\circledR}$ tablets were accurately weighted, powdered, and mixed well. The weight equivalent to one tablet was transferred into a $50 \mathrm{~mL}$ volumetric flask, and the volume was completed using distilled water. Then, further dilution with the same solvent was carried out to achieve a concentration of 10 and $150 \mu \mathrm{g} / \mathrm{mL}$ of CPM and PSE, respectively (IBF is sparingly soluble in water). The fabricated sensors (3 and 6) were dipped in the solution and were kept under constant stirring using a magnetic stirrer throughout the whole process. The sensors were in conjunction with the $\mathrm{Ag} / \mathrm{AgCl}$ reference electrode.

2.4.8. Determination of CPM and PSE in Spiked Human Plasma. One milliliter of the working standard solutions of $\mathrm{CPM}$ and PSE equivalent to $10^{-5}, 10^{-6}$, and $10^{-7} \mathrm{M}$ was added individually into a set of stoppered tubes comprising $9 \mathrm{~mL}$ of human plasma, and then the tubes were shaken for $1 \mathrm{~min}$. The fabricated sensors (3 and 6) were dipped in the plasma solutions and were kept under constant stirring using a magnetic stirrer throughout the whole process. The sensors were in conjunction with the $\mathrm{Ag} / \mathrm{AgCl}$ reference electrode. The acquired potential values were measured, and the concentrations of CPM and PSE were calculated from the corresponding previously computed regression equations.

\section{Results and Discussion}

Magnetite $\mathrm{Fe}_{3} \mathrm{O}_{4}$ nanoparticle is currently one of the most widespread magnetic nanoparticles which are extensively utilized in several applications. Based on the specific properties of nanoparticles, including their extreme small size, large surface area to volume ratio, and non-existence of internal diffusion resistance, this has led to providing improved kinetics for adsorbing contaminants from aqueous 
solutions [30]. Besides, the insertion of $\beta$-CD on the surface of magnetic nanoparticles was expected to enhance both their stability and dispersion in aqueous solutions, thus leading to increase in their surface areas and consequently improving their adsorption capacities [31-33].

The magnetic nanoparticles utilized in the presented study were manufactured by a classical coprecipitation method using $\beta$-CD as ionophoric polymer [34]. Through the inclusion of the prepared magnetic fluids into the inner solution of the membrane electrode, this would allow for the prompt and symmetric dispersion of the ion exchangerfunctionalized magnetic nanoparticles in the solution $[26,35]$. When a magnetic field is applied, the magnetic nanoparticles will be aggregated to the inner side of the polymeric membrane while the adsorbed ionophore and plasticizer on the nanoparticles will dissolve on the surface of the membrane resulting in a substantial potentiometric response [26, 35] (Figure 3).

The introduced work is devoted to evaluate the possibility of quantitative analysis of CPM and PSE by using ion selective electrode (ISE) sensors by means of PTA as ion exchanger, $\beta$-CD that forms host-guest inclusion complexes, and $\beta$-CD-conjugated $\mathrm{Fe}_{3} \mathrm{O}_{4}$ magnetic nanoparticles. A comparative study was held between traditional potentiometric strategy and potentiometric detection strategy based on functionalized $\mathrm{Fe}_{3} \mathrm{O}_{4}$ magnetic nanoparticles showing their advantages. The performance characteristics of the fabricated sensors were assessed in accordance with the IUPAC recommendations [36].

3.1. Sensors Fabrication. Generally, the solubility product of PTA ionic exchangers is low and it has suitable grain size. CPM and PSE were found to react as a monovalent cation, and they formed $3: 1$ ion association complex with PTA which was confirmed both by elemental analysis (Table 1) as well as by the achieved Nernstian slopes.

\subsection{Sensors Performance Characteristics and Response Time.} The electrochemical performance characteristics of the examined CPM and PSE sensors were assessed in accordance with the IUPAC recommendations [36] where the obtained results are abridged in Table 3. Typical calibration plots are demonstrated in Figure 4. As the electrodes responds mainly to the activity of the analytes (as cations) rather than their concentration, the slopes of the calibration plots have displayed a deviation from the ideal Nernstian slope $(60 \mathrm{mV})$. The slopes of the calibration plots were 54.60, 55.10, 53.70, and $55.00 \mathrm{mV} /$ concentration decade for sensors $(1,2,4$, and 5), respectively. However, $\mathrm{Fe}_{3} \mathrm{O}_{4}$ electrodes have exhibited the nearest value to the ideal Nernstian slope with the values of 58.17 and $57.79 \mathrm{mV} /$ concentration for sensors ( 3 and 6), respectively. The investigated $\mathrm{Fe}_{3} \mathrm{O}_{4}$ electrodes have demonstrated constant potential values in between different measurements where the slopes of the calibration curves were not altered by more than $\pm 2 \mathrm{mV} /$ decade throughout the stability periods of the developed sensors. Additionally, the slopes were not changed significantly but revealed a gradual decrease in sensitivity.
The examined $\mathrm{Fe}_{3} \mathrm{O}_{4}$ electrodes have displayed a fast response time. The time desired by the electrodes to accomplish $\pm 1 \mathrm{mV}$ values of the equilibrium potential after increasing the analytes concentration to 10 -folds was about $5-10 \mathrm{~s}$.

3.3. Effect of $p H$. In order to optimize the experimental conditions to allow for the quantitative analysis with the ion selective electrodes, the effect of $\mathrm{pH}$ on the response of the examined electrodes was investigated using $1 \times 10^{-4}$ and $1 \times 10^{-3} \mathrm{M}$ solutions of CPM and PSE. The potential-pH profile for sensors $(1,2$, and 3$)$ has demonstrated that the responses were fairly constant within the $\mathrm{pH}$ range 4-8, whereas the responses of the sensors $(4,5$, and 6$)$ were constant within the $\mathrm{pH}$ range $4-7$. The effect of $\mathrm{pH}$ on the responses of the developed electrodes is illustrated in Figure 5.

3.4. Sensors Selectivity. The potentiometric selectivity coefficients of the investigated sensors in the presence of coformulated drug (IBF), excipients present in the pharmaceutical formulations in addition to some inorganic cations such as $\mathrm{K}^{+}, \mathrm{Na}^{+}$, and $\mathrm{Ca}^{2+}$ which are normally present in biological fluids, are all demonstrated in Table 4. The obtained results have revealed that the $\mathrm{Fe}_{3} \mathrm{O}_{4}$ sensors ( 3 and 6) exhibited higher selectivity than the classical sensors $(1,2,4$, and 5$)$ for the quantitative analysis of CPM and PSE.

The proposed method was validated according to $\mathrm{ICH}$ guidelines, and it was found to be linear within the ranges from $10^{-8}$ to $10^{-2}$ with correlation coefficient close to one. The method displayed good accuracy and precision, where the accuracy was found to be between 99.45 and 101.85 and precision was less than 2 . The calculated LOD was found to be $5 \times 10^{-8}$ for sensor 3 and $4 \times 10^{-9}$ for sensor 6 which indicates the sensitivity of the proposed method. Due to these obtained promising results, the method was applied for the estimation of CPM and PSE both in pharmaceutical formulation and human plasma.

3.5. Potentiometric Determination of CPM and PSE in Pharmaceutical Formulation. Due to the higher selectivity of the $\mathrm{Fe}_{3} \mathrm{O}_{4}$ sensors ( 3 and 6), they were applied for the quantitative determination of CPM and PSE in tablet dosage form, where the recovery $\% \pm$ S.D. was found to be $102.26 \pm 1.204$ and $101.09 \pm 1.106$ for CPM and PSE, respectively. The obtained results were compared by using the reported method and verified the ability of the proposed sensors to be applied for the potentiometric estimation of the target drugs with no interference from IBF as a coformulated drug or from the commonly used excipients (Table 5).

\subsection{Potentiometric Determination of CPM and PSE in Spiked} Human Plasma. $\mathrm{Fe}_{3} \mathrm{O}_{4}$ sensors (3 and 6) were more sensitive for the analysis of CPM and PSE in spiked human plasma. The achieved results for the determination of these drugs have demonstrated that a wide concentration range of the drugs could be analyzed by the sensors under 


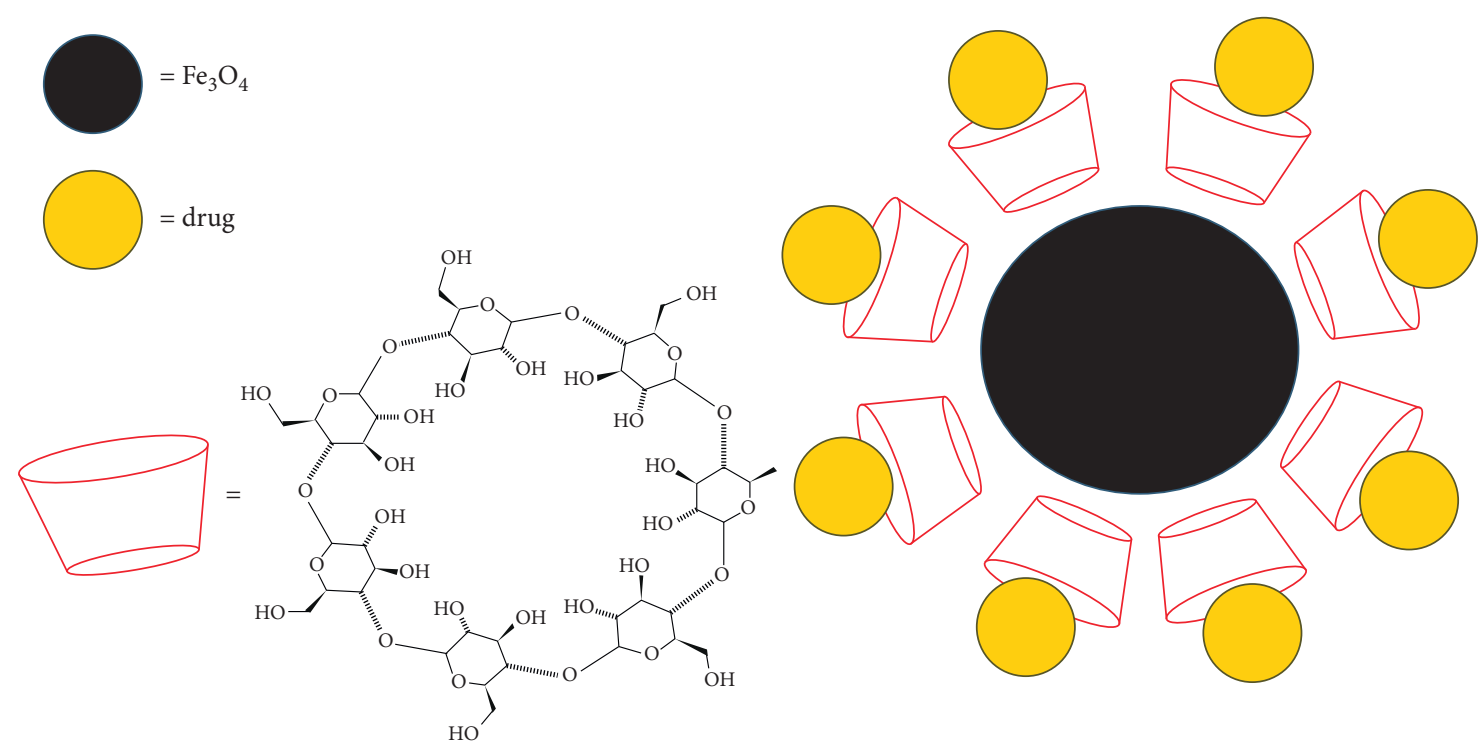

FIgURE 3: Schematic diagram representing the functionalization of $\mathrm{Fe}_{3} \mathrm{O}_{4}$ nanoparticles.

TABLE 3: Electrochemical response characteristics of the six investigated membrane sensors.

\begin{tabular}{|c|c|c|c|c|c|c|}
\hline Parameters & Sensor 1 & Sensor 2 & Sensor 3 & Sensor 4 & Sensor 5 & Sensor 6 \\
\hline Linearity $\left(\mathrm{mol} \cdot \mathrm{L}^{-1}\right)$ & $10^{-5}-10^{-2}$ & $10^{-5}-10^{-2}$ & $10^{-7}-10^{-2}$ & $10^{-5}-10^{-2}$ & $10^{-6}-10^{-2}$ & $10^{-8}-10^{-2}$ \\
\hline Correlation coefficient & 0.9992 & 0.9994 & 0.9996 & 0.9993 & 0.9994 & 0.9995 \\
\hline Slope $\left(\mathrm{mV} \cdot \text { decade }^{-1}\right)^{\mathrm{a}}$ & 54.6 & 55.10 & 58.17 & 53.70 & 55.00 & 57.79 \\
\hline Intercept $(\mathrm{mV})^{\mathrm{a}}$ & 179.6 & 167.10 & 316.77 & 177.2 & 154.2 & 274.79 \\
\hline Average recovery $(\text { mean } \pm S D)^{a}$ & $100.04 \pm 0.886$ & $99.89 \pm 0.783$ & $99.97 \pm 1.068$ & $100.06 \pm 0.897$ & $100.12 \pm 1.256$ & $100.01 \pm 1.026$ \\
\hline $\operatorname{LOD}\left(\mathrm{mol} \cdot \mathrm{L}^{-1}\right)^{\mathrm{b}}$ & $8 \times 10^{-6}$ & $9.1 \times 10^{-6}$ & $5 \times 10^{-8}$ & $7 \times 10^{-6}$ & $6.9 \times 10^{-6}$ & $4 \times 10^{-9}$ \\
\hline Accuracy $($ mean $\pm S D)$ & $101.85 \pm 1.258$ & $100.66 \pm 1.347$ & $100.98 \pm 0.813$ & $101.68 \pm 0.985$ & $101.64 \pm 1.313$ & $99.45 \pm 0.973$ \\
\hline \multicolumn{7}{|l|}{ Precision (RSD \%) } \\
\hline Intraday & 1.023 & 0.998 & 0.944 & 1.183 & 0.994 & 0.846 \\
\hline Interday & 1.155 & 1.117 & 0.819 & 1.063 & 0.789 & 0.716 \\
\hline Response time (sec) & $10-15$ & $15-20$ & $5-10$ & $10-15$ & $10-15$ & $5-10$ \\
\hline Working $\mathrm{pH}$ range & $4-8$ & $4-8$ & $4-8$ & $4-7$ & $4-7$ & $4-7$ \\
\hline Stability (days) & 15 & 20 & 30 & 20 & 25 & 40 \\
\hline
\end{tabular}

${ }^{a}$ Average of five determinations; ${ }^{b}$ limit of detection (measured by interception of the extrapolated arms of Figure 2).

investigation with high accuracy and precision as abridged in Table 6.

The response time of the $\mathrm{Fe}_{3} \mathrm{O}_{4}$ sensors was instant (within $5 \mathrm{~s}$ ), so the sensors were quickly moved between the biological samples and the deionized water in between the measurements in order to prevent the sensing components from adherence on the surface of certain matrix components. It was obvious that the proposed $\mathrm{Fe}_{3} \mathrm{O}_{4}$ sensors could be utilized effectively for in vitro studies. A core benefit of these sensors is their ability to directly determine the target drugs in human plasma samples without the need for any prior treatment or extraction.

As final conclusion, electrodes based on functionalized $\mathrm{Fe}_{3} \mathrm{O}_{4}$ magnetic nanoparticles (sensors 3 and 6) were found to be superior over classical electrodes (sensors 1, 2, 4, and 5) regarding sensitivity (lower LOD), selectivity, response time, and stability.

\section{Statistical Analysis}

Statistical comparison was performed between the six fabricated sensors and a reported method [23] for the analysis of CPM and PSE. As the calculated $t$ and $F$ values were found to be less than the theoretical values, it was concluded that there was no significant difference as demonstrated in $\mathrm{Ta}$ ble 7. One-way ANOVA was also done to ascertain the absence of significant difference between the obtained results of the different proposed sensors (Table 8).

\section{Conclusion}

This work presented a comparative study between potentiometric detection strategy based on functionalized $\mathrm{Fe}_{3} \mathrm{O}_{4}$ magnetic nanoparticles versus classical potentiometric strategy for the quantitative estimation of CPM and PSE. The 


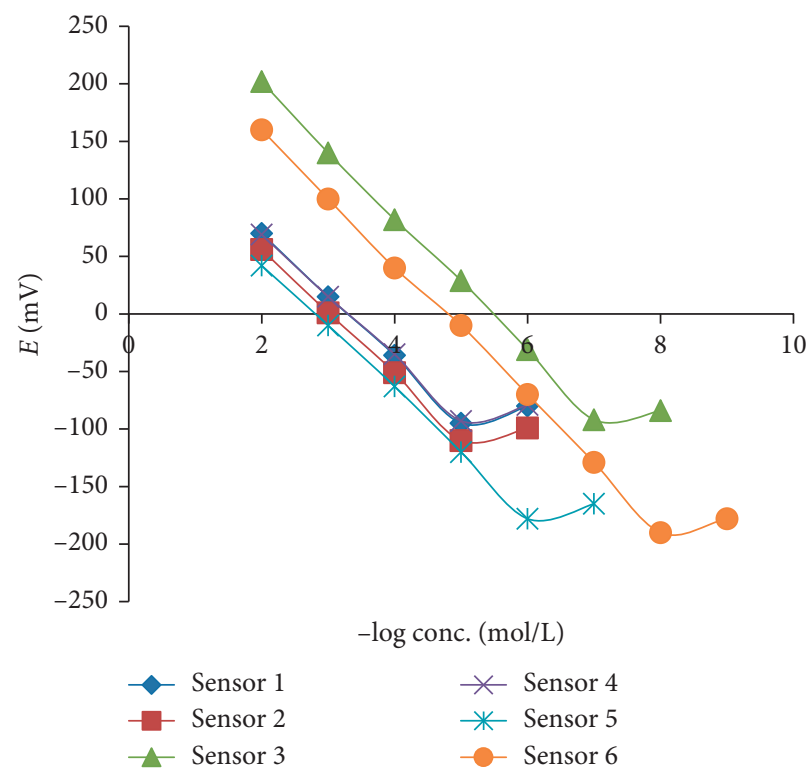

FIGURE 4: Profile of the potential in $\mathrm{mV}$ to $-\log$ concentration of CPM and PSE in mol/L obtained with the proposed sensors.

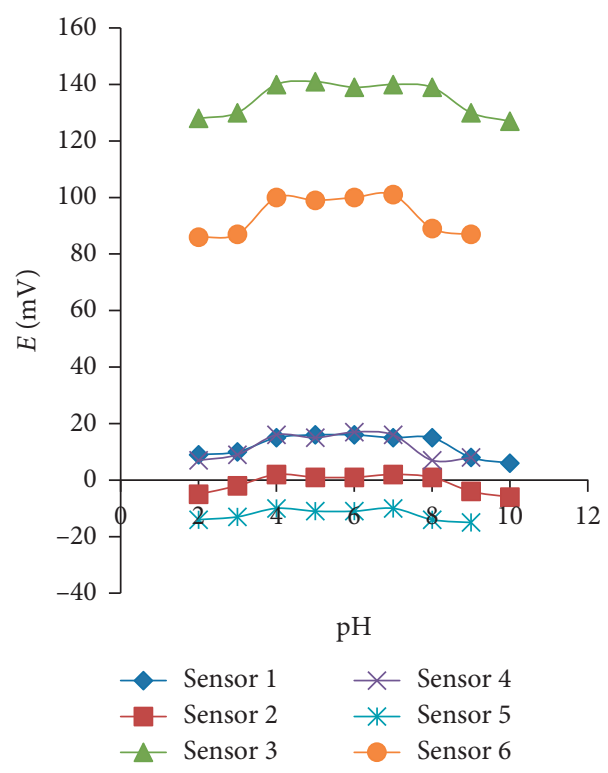

(a)

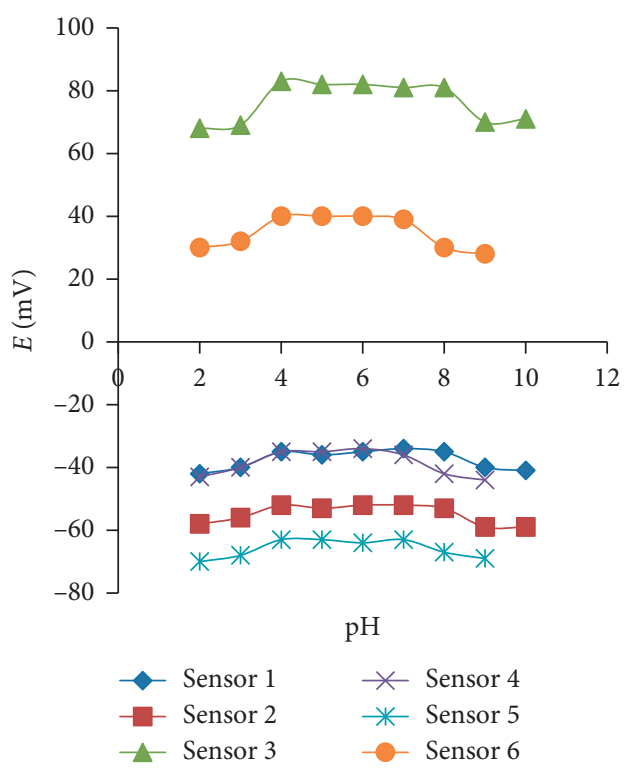

(b)

FIGURE 5: The effect of $\mathrm{pH}$ on the developed sensors using (a) $10^{-3} \mathrm{M}$ and (b) $10^{-4} \mathrm{M}$ of CPM and PSE solution.

TABle 4: Potentiometric selectivity coefficients $\left(K^{\text {pot. }}\right)$ of the six proposed sensors by using the separate solutions method.

\begin{tabular}{|c|c|c|c|c|c|c|}
\hline Interferent & Sensor 1 & Sensor 2 & Sensor 3 & Sensor 4 & Sensor 5 & Sensor 6 \\
\hline $\mathrm{NaCl}$ & $4.51 \times 10^{-3}$ & $3.67 \times 10^{-3}$ & $2.14 \times 10^{-4}$ & $3.17 \times 10^{-2}$ & $3.26 \times 10^{-2}$ & $4.57 \times 10^{-4}$ \\
\hline $\mathrm{KCl}$ & $6.47 \times 10^{-3}$ & $3.43 \times 10^{-3}$ & $2.25 \times 10^{-4}$ & $4.52 \times 10^{-2}$ & $3.42 \times 10^{-2}$ & $5.51 \times 10^{-4}$ \\
\hline $\mathrm{CaCl}_{2}$ & $3.22 \times 10^{-3}$ & $4.27 \times 10^{-3}$ & $2.67 \times 10^{-4}$ & $3.63 \times 10^{-2}$ & $2.68 \times 10^{-2}$ & $3.17 \times 10^{-4}$ \\
\hline $\mathrm{CPM}^{2}$ & - & - & - & $5.72 \times 10^{-2}$ & $2.33 \times 10^{-3}$ & $6.45 \times 10^{-4}$ \\
\hline PSE & $3.17 \times 10^{-1}$ & $3.89 \times 10^{-2}$ & $8.77 \times 10^{-3}$ & - & - & - \\
\hline IBF & $6.83 \times 10^{-1}$ & $6.51 \times 10^{-2}$ & $9.25 \times 10^{-3}$ & $6.83 \times 10^{-2}$ & $4.47 \times 10^{-3}$ & $7.48 \times 10^{-4}$ \\
\hline
\end{tabular}

performance characteristics of the developed sensors were assessed in compliance with the IUPAC recommendations. All the fabricated sensors were satisfactorily simple and selective for the determination of CPM and PSE. The $\mathrm{Fe}_{3} \mathrm{O}_{4}$ sensors have advantages over the membrane sensors of being more sensitive and selective and of having faster response 
TABLE 5: Determination of CPM and PSE in pharmaceutical formulation by the proposed sensors and comparison with the reported method.

\begin{tabular}{|c|c|c|c|c|}
\hline Pharmaceutical formulation & & Sensor 3 & Sensor 6 & Reported method [23] \\
\hline $\begin{array}{l}\text { Sinlerg }{ }^{\circledR} \text { tablets labelled to contain } 2 \mathrm{mg} \mathrm{CPM}, 30 \mathrm{mg} \\
\text { PSE, and } 200 \mathrm{mg} \text { IBF/tablet (batch no. } 212314 \text { ) }\end{array}$ & $\begin{array}{c}\text { Mean } \pm \mathrm{SD}^{\mathrm{a}} \\
\text { Student's } t \text { test } \\
F \text { test }\end{array}$ & $\begin{array}{c}102.26 \pm 1.204 \\
0.518\left(2.26^{\mathrm{b}}\right) \\
1.623\left(6.26^{\mathrm{b}}\right)\end{array}$ & $\begin{array}{c}101.09 \pm 1.106 \\
0.743\left(2.26^{\mathrm{b}}\right) \\
1.182\left(6.26^{\mathrm{b}}\right)\end{array}$ & $100.63 \pm 1.317$ \\
\hline
\end{tabular}

${ }^{a}$ Average of five determinations. ${ }^{b}$ Reported HPLC method using C18 column; flow rate $1.5 \mathrm{~mL} \cdot \mathrm{min}^{-1}$; mobile phase is a gradient elution of acetonitrile:buffer $(15: 85, \mathrm{v} / \mathrm{v})$ for $5.5 \mathrm{~min},(45: 55, \mathrm{v} / \mathrm{v})$ for $5.5-12 \mathrm{~min}$, and $(60: 40, \mathrm{v} / \mathrm{v})$ for $12-17 \mathrm{~min}$ at $\mathrm{pH}=3$ and $\mathrm{UV}$ detection at $220 \mathrm{~nm}$.

TABLE 6: Determination of CPM and PSE in spiked human plasma by the proposed sensors 3 and 6.

\begin{tabular}{|c|c|c|}
\hline \multirow{3}{*}{ Drug concentration } & \multicolumn{2}{|c|}{ Spiked human plasma } \\
\hline & Sensor 3 & Sensor 6 \\
\hline & \multicolumn{2}{|c|}{ Recovery $(\%) \pm$ SD $^{*}$} \\
\hline $10^{-5} \mathrm{M}$ & $101.12 \pm 0.716$ & $100.41 \pm 1.215$ \\
\hline $10^{-6} \mathrm{M}$ & $100.60 \pm 1.158$ & $100.31 \pm 1.040$ \\
\hline $10^{-7} \mathrm{M}$ & $101.78 \pm 0.618$ & $101.39 \pm 0.622$ \\
\hline
\end{tabular}

${ }^{*}$ The recovery percentages are the average of three determinations.

TABLE 7: Statistical comparison between the results obtained by the proposed sensors and the reported method for the determination of CPM and PSE in pure form.

\begin{tabular}{|c|c|c|c|c|c|c|c|}
\hline & Parameter & Mean $^{a}$ & SD & Variance & $n$ & $t$ test & $F$ test \\
\hline \multirow{4}{*}{$\mathrm{CPM}$} & Sensor 1 & 100.04 & 0.886 & 0.785 & 4 & $0.484\left(2.36^{\mathrm{b}}\right)$ & $1.445\left(9.12^{\mathrm{b}}\right)$ \\
\hline & Sensor 2 & 99.89 & 0.783 & 0.613 & 4 & $0.265\left(2.36^{\mathrm{b}}\right)$ & $1.850\left(9.12^{\mathrm{b}}\right)$ \\
\hline & Sensor 3 & 99.97 & 1.068 & 1.141 & 6 & $0.384\left(2.26^{\mathrm{b}}\right)$ & $1.006\left(6.26^{b}\right)$ \\
\hline & Reported method $[23]^{\mathrm{c}}$ & 99.72 & 1.065 & 1.134 & 5 & & \\
\hline \multirow{4}{*}{ PSE } & Sensor 4 & 100.06 & 0.897 & 0.804 & 4 & $0.943\left(2.36^{\mathrm{b}}\right)$ & $1.271\left(9.12^{\mathrm{b}}\right)$ \\
\hline & Sensor 5 & 100.12 & 1.256 & 1.577 & 5 & $0.944\left(2.31^{\mathrm{b}}\right)$ & $1.543\left(6.39^{b}\right)$ \\
\hline & Sensor 6 & 100.01 & 1.026 & 1.052 & 7 & $0.951\left(2.23^{\mathrm{b}}\right)$ & $1.029\left(6.16^{\mathrm{b}}\right)$ \\
\hline & Reported method $[23]^{\mathrm{c}}$ & 99.45 & 1.011 & 1.022 & 5 & & \\
\hline
\end{tabular}

${ }^{a}$ Average of six determinations; ${ }^{\mathrm{b}}$ figures between parentheses represent the corresponding tabulated values of $t$ and $F$ at $P=0.05$; ${ }^{\mathrm{c}}$ reported HPLC method using C18 column, flow rate $1.5 \mathrm{~mL} \cdot \mathrm{min}^{-1}$, mobile phase is a gradient elution of acetonitrile:phosphate buffer $(15: 85, \mathrm{v} / \mathrm{v})$ for $5.5 \mathrm{~min},(45: 55, \mathrm{v} / \mathrm{v})$ for $5.5-12 \mathrm{~min}$, and $(60: 40, \mathrm{v} / \mathrm{v})$ for $12-17 \mathrm{~min}$ at $\mathrm{pH}=3$ and UV detection at $220 \mathrm{~nm}$.

TABLE 8: One-way ANOVA testing for the different proposed methods and the reported method used for the determination of CPM and PSE.

\begin{tabular}{|c|c|c|c|c|c|c|c|}
\hline & Source & Sum of squares & Degree of freedom ${ }^{a}$ & Mean squares & $F$ value $^{\mathrm{b}}$ & $P$ value & $F$ critical \\
\hline \multirow{2}{*}{ PSE } & Between experiment & 0.2618 & 3 & 0.0873 & 0.0750 & 0.9726 & 3.1968 \\
\hline & Within experiment & 19.7883 & 17 & 1.1640 & & & \\
\hline \multirow{2}{*}{ CPM } & Between experiment & 0.1858 & 3 & 0.0619 & 0.0609 & 0.9796 & 3.2874 \\
\hline & Within experiment & 15.2688 & 15 & 1.0179 & & & \\
\hline
\end{tabular}

${ }^{a}$ At the 0.05 level; ${ }^{b}$ the population means are not significantly different.

and higher stability. The $\mathrm{Fe}_{3} \mathrm{O}_{4}$ sensors were effectively applied for the analysis of CPM and PSE in both pharmaceutical formulation and spiked human plasma. No interference was observed from coformulated drugs, additives commonly used in dosage form and inorganic substances. The proposed sensors introduced certain advantages as being accurate and do not require drug pretreatment or separation steps which offers a cost-effective method of analysis allowing this method to be used in CPM and PSE routine analysis in quality control laboratories.

\section{Data Availability}

All the data are included in the manuscript in the form of provided tables and figures.

\section{Conflicts of Interest}

The authors declare that there are no conflicts of interest regarding the publication of this paper.

\section{References}

[1] S. U. Yasuda, A. Wellstein, P. Likhari, J. T. Barbey, and R. L. Woosley, "Chlorpheniramine plasma concentration and histamine H1-receptor occupancy*," Clinical Pharmacology \& Therapeutics, vol. 58, no. 2, pp. 210-220, 1995.

[2] L. S. Goodman and A. G. Gilman, Goodman and Gilman's the Pharmaceutical Basis of Therapeutics, Macmillan Publishing Company, New York, NY, USA, 9th edition, 1996.

[3] A. Van Esch, H. A. Van Steensel-Moll, E. W. Steyerberg, M. Offringa, J. D. Habbema, and G. Derksen-Lubsen, 
"Antipyretic efficacy of ibuprofen and acetaminophen in children with febrilsse seizures," Archives of Pediatrics \& Adolescent Medicine, vol. 149, no. 6, pp. 632-637, 1995.

[4] J. L. Murtha, T. N. Julian, and G. W. Radebaugh, "Simultaneous determination of pseudoephedrine hydrochloride, chlorpheniramine maleate, and dextromethorphan hydrobromide by second-derivative photodiode array spectroscopy," Journal of Pharmaceutical Sciences, vol. 77, no. 8, pp. 715-718, 1988.

[5] I. M. Palabiyik, E. Dinç, and F. Onur, "Simultaneous spectrophotometric determination of pseudoephedrine hydrochloride and ibuprofen in a pharmaceutical preparation using ratio spectra derivative spectrophotometry and multivariate calibration techniques," Journal of Pharmaceutical and Biomedical Analysis, vol. 34, no. 3, pp. 473-483, 2004.

[6] S. Chitlange, D. Sakarkar, S. Wankhede, and S. Wadodkar, "High performance thin layer chromatographic method for simultaneous estimation of ibuprofen and pseudoephedrine hydrochloride," Indian Journal of Pharmaceutical Sciences, vol. 70, no. 3, pp. 398-400, 2008.

[7] X. Chen, Y. Zhang, and D. Zhong, "Simultaneous determination of chlorpheniramine and pseudoephedrine in human plasma by liquid chromatography-tandem mass spectrometry," Biomedical Chromatography, vol. 18, no. 4, pp. 248-253, 2004.

[8] H.-g. Lou, H. Yuan, Z.-r. Ruan, and B. Jiang, "Simultaneous determination of paracetamol, pseudoephedrine, dextrophan and chlorpheniramine in human plasma by liquid chromatography-tandem mass spectrometry," Journal of Chromatography B, vol. 878, no. 7, pp. 682-688, 2010.

[9] J. A. Thompson and F. H. Leffert, "Sensitive GLC-mass spectrometric determination of chlorpheniramine in serum," Journal of pharmaceutical sciences, vol. 69, no. 6, pp. 707-710, 1980.

[10] M. Louhaichi, S. Jebali, M. Loueslati, N. Adhoum, and L. Monser, "Simultaneous determination of pseudoephdrine, pheniramine, guaifenisin, pyrilamine, chlorpheniramine and dextromethorphan in cough and cold medicines by high performance liquid chromatography," Talanta, vol. 78, no. 3, pp. 991-997, 2009.

[11] Y. Dong, X. Chen, Y. Chen, X. Chen, and Z. Hu, "Separation and determination of pseudoephedrine, dextromethorphan, diphenhydramine and chlorpheniramine in cold medicines by nonaqueous capillary electrophoresis," Journal of Pharmaceutical and Biomedical Analysis, vol. 39, no. 1-2, pp. 285-289, 2005.

[12] Y. Liu and W. Zhou, "Determination of chlorpheniramine and its binding with human serum albumin by capillary electrophoresis with Tris(2,2'-bipyridyl)ruthenium(II) electrochemiluminescence detection," Analytical Sciences, vol. 22, no. 7, pp. 999-1003, 2006.

[13] C.-L. Huang, J.-J. Ren, and D.-F. Xu, "Studies of the chlorpheniramine solid-state ion-selective electrode," Talanta, vol. 43, no. 12, pp. 2061-2065, 1996.

[14] A. Qu, D. Xu, L. Ren, X. Jin, and S. Cai, "Construction and application of an all-solid-state chlorphenigramine ionselective electrode," Electroanalysis, vol. 4, no. 3, pp. 355358, 1992.

[15] H. M. Abu-Shawish, "Potentiometric response of modified carbon paste electrode based on mixed ion-exchangers," Electroanalysis, vol. 20, no. 5, pp. 491-497, 2008.

[16] Y. Long, W. Li, L. Nie, and S. Yao, "Preparation and application of chlorpheniramine ion-selective piezoelectric sensor based on selective adsorption," Analytica Chimica Acta, vol. 395, no. 1-2, pp. 33-40, 1999.

[17] M. R. Ganjali, A. Alipour, S. Riahi, B. Larijani, and P. Norouzi, "Quantitative analysis of pseudoephedrine in formulation by potentiometric membrane sensor; computational investigation," International Journal of Electrochemical Science, vol. 4, no. 9, pp. 1262-1276, 2009.

[18] S. Zayed, Y. Issa, and A. Hussein, "Construction and performance characterization of ionselective electrodes for potentiometric determination of pseudoephedrine hydrochloride applying batch and flow injection analysis techniques," Annali di chimica, vol. 96, no. 7-8, pp. 421-433, 2006.

[19] M. Giahi, M. Arvand, M. Mirzaei, and M. Ali Bagherinia, "Determination of pseudoephedrine hydrochloride in some pharmaceutical drugs by potentiometric membrane sensor based on pseudoephedrine-phosphotungstate ion pair," Analytical Letters, vol. 42, no. 6, pp. 870-880, 2009.

[20] S. S. Hassan, W. H. Mahmoud, and M. S. Abdel-Samad, "Direct potentiometry and potentiotitrimetry of warfarin and ibuprofen in pharmaceutical preparations using PVC ferroinbased membrane sensors," Mikrochimica Acta, vol. 129, no. 34, pp. 251-257, 1998.

[21] Q. Wang, S. Li, X. Che, X. Fan, and C. Li, "Dissolution improvement and stabilization of ibuprofen by co-grinding in a $\beta$-cyclodextrin inclusion ground complex," Asian Journal of Pharmaceutical Sciences, vol. 5, pp. 188-193, 2010.

[22] D. D. Chow and A. H. Karara, "Characterization, dissolution and bioavailability in rats of ibuprofen- $\beta$-cyclodextrin complex system," International Journal of Pharmaceutics, vol. 28, no. 2-3, pp. 95-101, 1986.

[23] B. Aşçi, Ö. A. Dönmmez, A. Bozdoğan, and S. Sungur, "Experimental design of reversed-phase high performance liquid chromatographic conditions for simultaneous determination of ibuprofen, pseudoephedrine hydrochloride, chlorpheniramine maleate, and nipagen," Journal of Analytical Chemistry, vol. 65, no. 7, pp. 743-748, 2010.

[24] R.-I. Stefan-van Staden and M. N. R'afat, "Cyclodextrinsbased enantioselective, potentiometric membrane electrodes for l-vesamicol assay in serum samples," Sensors and Actuators B: Chemical, vol. 117, no. 1, pp. 123-127, 2006.

[25] A. M. El-Kosasy, O. A. El-Aziz, N. Ebrahim, and L. A. Fattah, "Novel potentiometric determination of torasemide for antidoping purpose, using $\beta$-cyclodextrin and calixarene," Analytical and Bioanalytical Chemistry, vol. 4, no. 4, pp. 357-371, 2012.

[26] D. A. Song, R. N. Liang, R. M. Zhang, J. W. Ding, J. Zhang, and W. Qin, "Potentiometric detection of polyions based on functionalized magnetic nanoparticles," Chinese Chemical Letters, vol. 21, no. 11, pp. 1378-1381, 2010.

[27] R. M. Kakhki, "Application of magnetic nanoparticles modified with cyclodextrins as efficient adsorbents in separation systems," Journal of Inclusion Phenomena and Macrocyclic Chemistry, vol. 82, no. 3-4, pp. 301-310, 2015.

[28] S. Palacin, P. C. Hidber, J.-P. Bourgoin, C. Miramond, C. Fermon, and G. M. Whitesides, "Patterning with magnetic materials at the micron scale," Chemistry of Materials, vol. 8, no. 6, pp. 1316-1325, 1996.

[29] P. Berger, N. B. Adelman, K. J. Beckman, D. J. Campbell, A. B. Ellis, and G. C. Lisensky, "Preparation and properties of an aqueous ferrofluid," Journal of Chemical Education, vol. 76, no. 7, p. 943, 1999. 
[30] S.-Y. Mak and D.-H. Chen, "Fast adsorption of methylene blue on polyacrylic acid-bound iron oxide magnetic nanoparticles," Dyes and Pigments, vol. 61, no. 1, pp. 93-98, 2004.

[31] C. Tudisco, V. Oliveri, M. Cantarella, G. Vecchio, and G. G. Condorelli, "Cyclodextrin anchoring on magnetic $\mathrm{Fe}_{3} \mathrm{O}_{4}$ nanoparticles modified with phosphonic linkers," European Journal of Inorganic Chemistry, vol. 2012, no. 32, pp. 53235331, 2012.

[32] R. Chalasani and S. Vasudevan, "Cyclodextrin functionalized magnetic iron oxide nanocrystals: a host-carrier for magnetic separation of non-polar molecules and arsenic from aqueous media," Journal of Materials Chemistry, vol. 22, no. 30, pp. 14925-14931, 2012.

[33] A. R. Kiasat and S. Nazari, " $\beta$-Cyclodextrin conjugated magnetic nanoparticles as a novel magnetic microvessel and phase transfer catalyst: synthesis and applications in nucleophilic substitution reaction of benzyl halides," Journal of Inclusion Phenomena and Macrocyclic Chemistry, vol. 76, no. 3-4, pp. 363-368, 2013.

[34] A. Kapor, V. Nikolić, L. Nikolić et al., "Inclusion complexes of amlodipine besylate and cyclodextrins," Open Chemistry, vol. 8, no. 4, pp. 834-841, 2010.

[35] A. M. El-Kosasy, S. M. Tawakkol, M. F. Ayad, and A. I. Sheta, "A novel potentiometric detection strategy for the determination of amlodipine besylate based on functionalized particles," Electroanalysis, vol. 26, no. 5, pp. 1031-1038, 2014.

[36] IUPAC, "Analytical chemistry division, commission on analytical nomenclature," Pure and Applied Chemistry, vol. 72, p. $1852,2000$. 

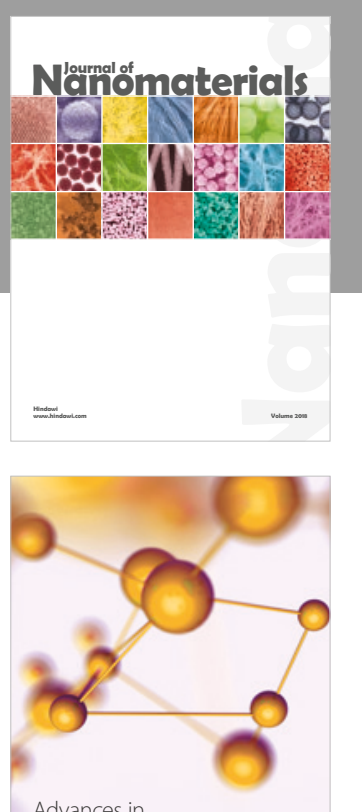

Physical Chemistry
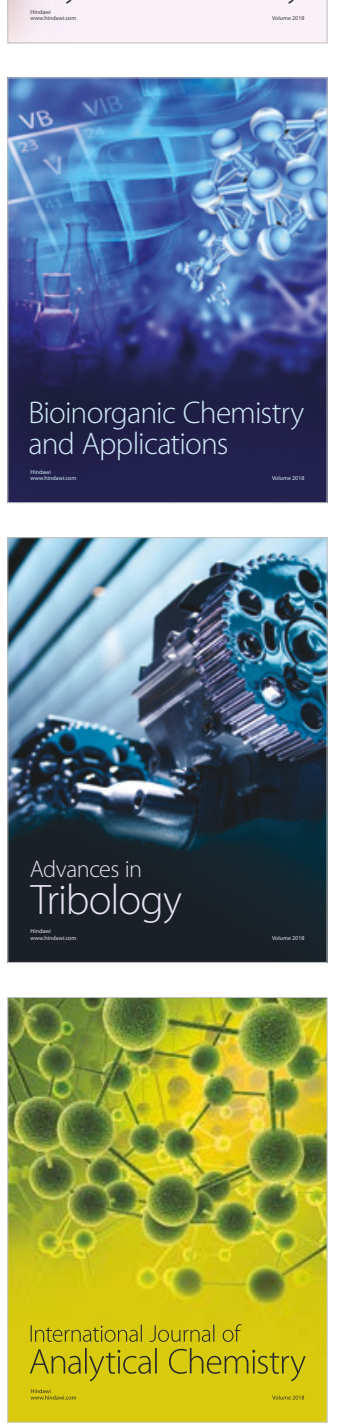

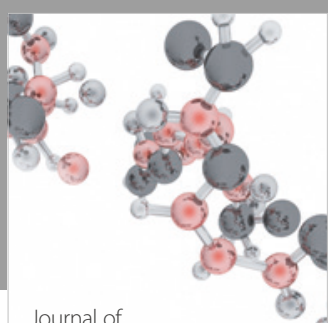

Analytical Methods

in Chemistry

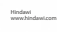

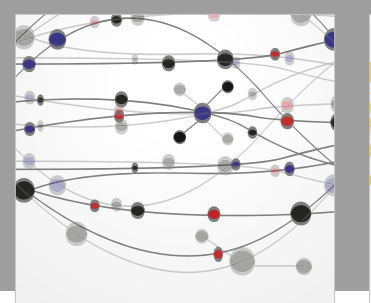

The Scientific World Journal

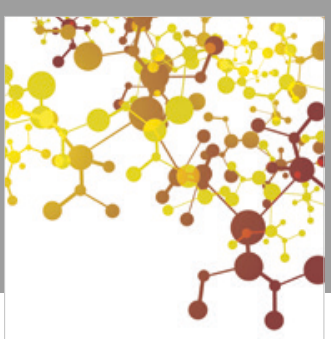

Journal of

Applied Chemistry
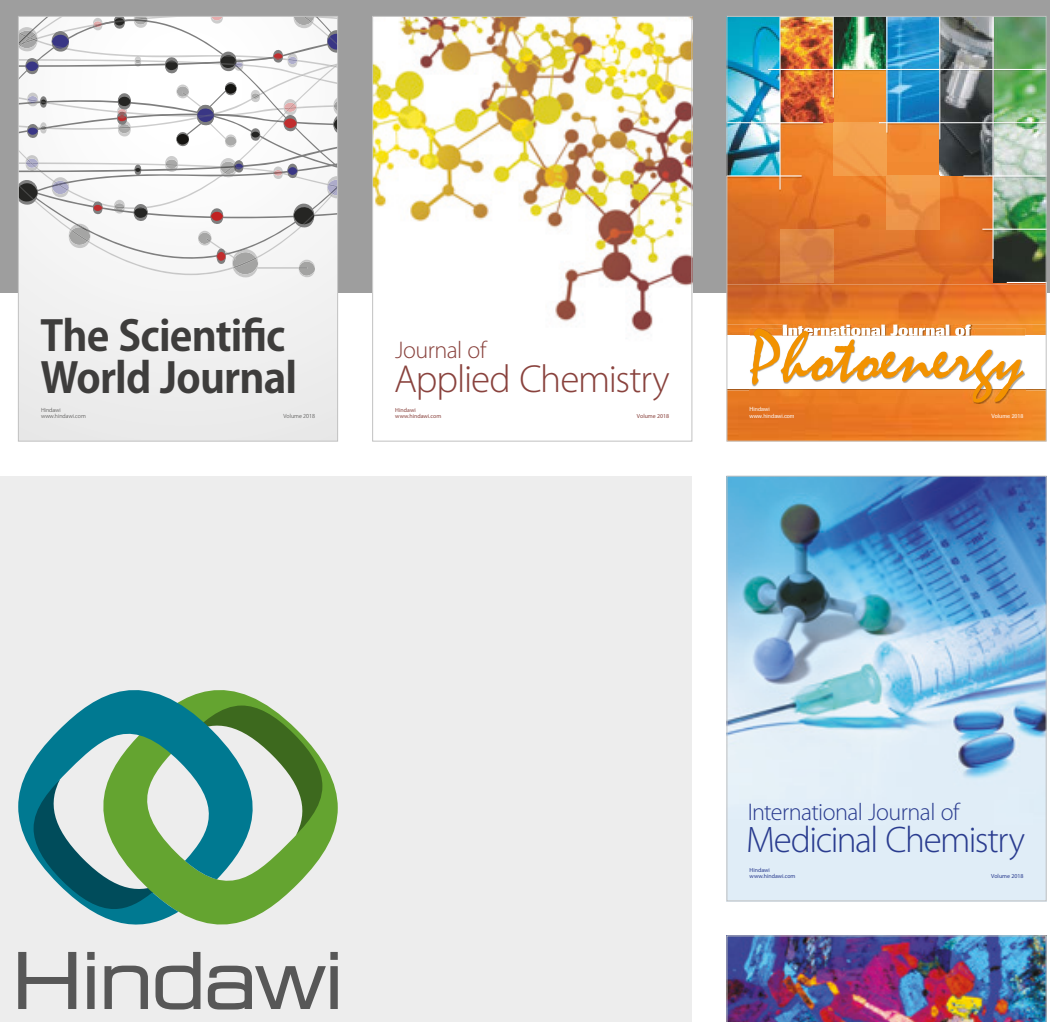

Submit your manuscripts at

www.hindawi.com
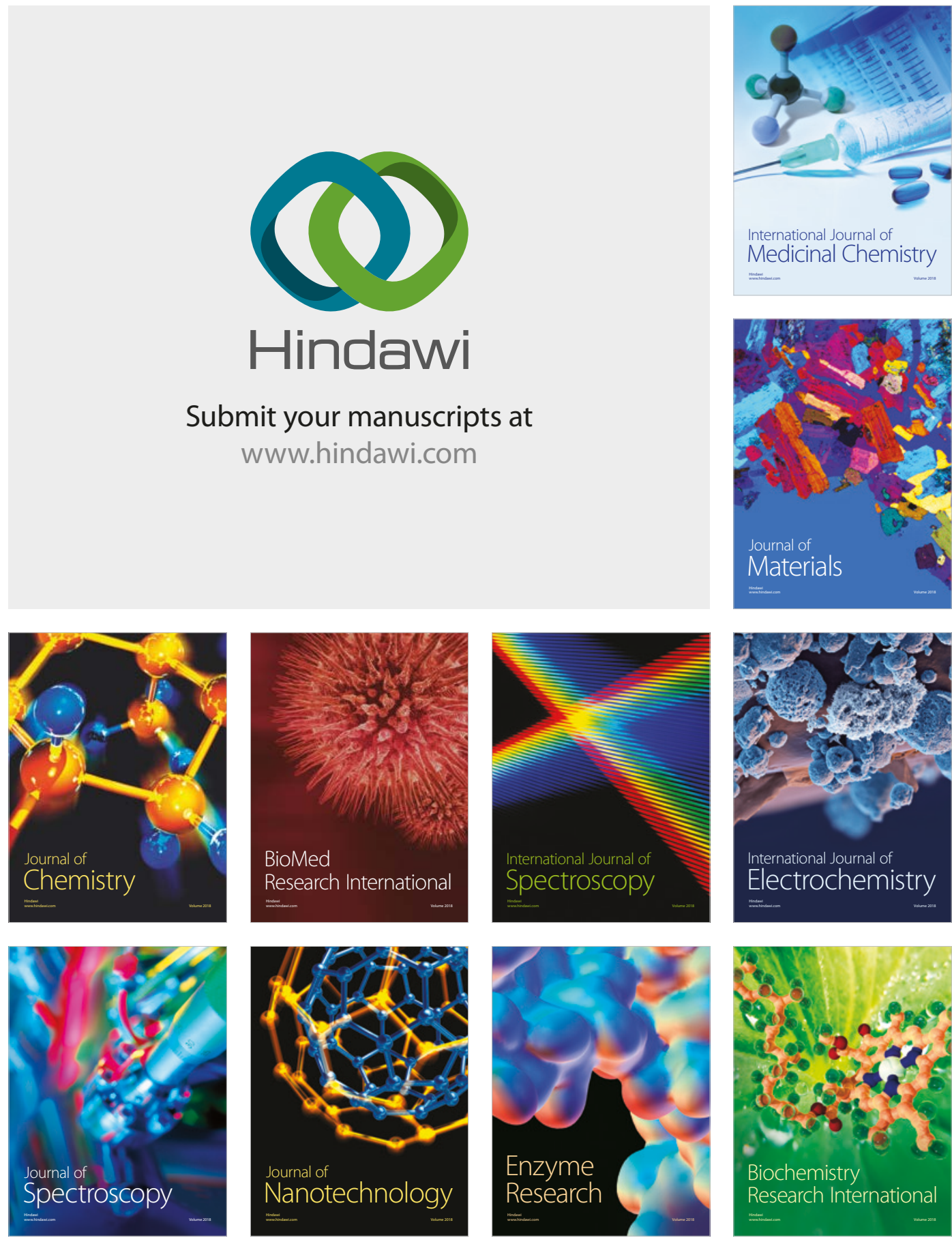
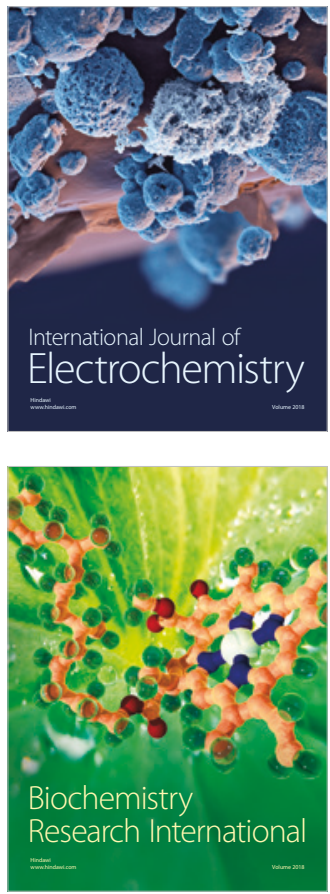